\title{
Un análisis del concepto de acoso sexual laboral: reflexiones y orientaciones para la investigación y la intervención social
}

\author{
Rocío PÉREZ GUARDO \\ Universidad de Valladolid \\ rociopg@soc.uva.es \\ Carmen RODRÍGUEZ SUMAZA \\ Universidad de Valladolid \\ sumaza@eco.uva.es
}

Recibido: 13-03-2012

Aceptado: 15-09-2012

\begin{abstract}
RESUMEN
El acoso sexual laboral es la temática principal de este artículo, realizado atendiendo a la necesidad de aportar más conocimientos sobre una realidad de indudable interés y relevancia que se ha ido configurando como un importante problema social en la esfera laboral. A partir de la revisión del proceso de identificación, conceptualización y tratamiento del fenómeno, se analizan algunas de las principales definiciones de acoso sexual laboral, constatando que no existe un claro consenso al respecto. A través de la deconstrucción del concepto, se identifican los principales elementos de la estructura conceptual, así como los posicionamientos y limitaciones de cada definición ante los mismos. El artículo concluye con una serie de propuestas y orientaciones que pretenden dar respuesta a los diversos interrogantes metodológicos que surgen a la hora de investigar e intervenir socialmente en esta compleja realidad.
\end{abstract}

Palabras clave: acoso sexual laboral, conceptualización, deconstrucción, investigación, intervención social

Analyzing the concept of sexual harassment in the workplace: key issues for research and social intervention

\begin{abstract}
Sexual harassment in the workplace is the main topic of this article, undertaken in response to the need to shed further light on a reality of undeniable interest and relevance that has become a major social problem in the labor market. From the review of the identification, conceptualization and treatment of the phenomenon, we analyse the main definitions of sexual harassment at workplace, confirming that there is no clear consensus. Through the deconstruction of the concept, we identify some of the main elements of the conceptual structure and the positions and limitations of each definition before them, trying to answer some of the methodological questions that arise in research and social intervention on this complex fact.
\end{abstract}

Keywords: sexual harassment in the workplace, conceptualization, deconstruction, research, social intervention 


\section{REFERENCIA NORMALIZADA}

Pérez Guardo, R. y Rodríguez Sumaza, C. (2012). Un análisis del concepto de acoso sexual laboral: reflexiones y orientaciones para la investigación y la intervención social. Cuadernos de Relaciones Laborales Vol. 31, Núm. 1, p. 195-219.

SUMARIO: Introducción. 1. El proceso de identificación, conceptualización y tratamiento del acoso sexual laboral. 1.1. Los orígenes del proceso. 1.2. El escenario internacional y europeo. 1.3. El ámbito nacional. 2. Una deconstrucción del concepto de acoso sexual laboral: reflexiones sobre su influencia en el diseño de investigaciones e intervenciones sociales. 2.1. La importancia del concepto de partida para la investigación y la intervención social. 2.2. Un análisis de los principales elementos conceptuales. 3. Orientaciones para la investigación y la intervención social. 4. Bibliografía.

\section{Introducción}

Este artículo aborda una problemática de indudable interés y relevancia social, el acoso sexual laboral, un fenómeno que emerge a partir del nuevo papel que pasan a desempeñar las mujeres en el mercado de trabajo español en las últimas décadas. Se trata, no obstante, de una realidad poco visible y conocida que requiere de estudios que nos permitan adentrarnos en su cuantificación y caracterización y en el diseño de medidas de intervención para su prevención y erradicación.

Atendiendo a dichas necesidades, en este artículo se aborda una cuestión controvertida y poco trabajada: el propio concepto de acoso sexual laboral. No se busca tanto ofrecer una definición alternativa a las existentes, como invitar a la reflexión sobre las limitaciones que éstas presentan y sus implicaciones a la hora de tratar de investigar e intervenir en esta compleja realidad. Se trata, en otras palabras, de realizar un análisis de las definiciones de acoso sexual manejadas con el objetivo de aportar reflexiones y orientaciones sobre ciertos parámetros útiles a la hora de diseñar investigaciones e intervenciones sociales respecto al fenómeno.

El texto se estructura en tres apartados. En primer lugar, partimos de una reconstrucción del proceso de identificación, conceptualización y tratamiento del fenómeno, realizado por diferentes organismos internacionales, el Derecho comunitario y español y diversos/as especialistas en la materia. En segundo lugar, se reflexiona sobre la importancia que tienen los conceptos de partida para la investigación y la intervención social y se procede a identificar y analizar los principales elementos conceptuales contenidos en las definiciones de acoso sexual laboral de referencia, evidenciando su potencial influencia en el diseño de investigaciones e intervenciones sociales. Finalmente, y con el fin de contribuir a la mejora del análisis de esa realidad social, se plantean a modo de conclusión y de una forma más específica una serie de interrogantes y orientaciones a tener en cuenta a la hora de investigar o intervenir sobre ella. 


\section{El proceso de identificación, conceptualización y tratamiento del acoso sexual laboral}

\subsection{Los orígenes del proceso}

El acoso sexual laboral ha ido adquiriendo en los últimos años una gran relevancia social. El fenómeno en sí no es un hecho novedoso. La novedad es el creciente interés por su identificación, conceptualización y tratamiento, tanto desde el escenario internacional como desde el comunitario y el nacional. Así, se ha ido dando nombre a una realidad que emerge a raíz de la reestructuración del sistema de roles atribuidos a los individuos por razón de su sexo, más concretamente a raíz de la progresiva incorporación de las mujeres al mercado de trabajo.

Con el fin de analizar la construcción social del acoso sexual laboral como problema social, hemos partido del estudio de una serie de conceptos relevantes que se han ido empleando para designar y delimitar ese hecho desde las ópticas jurídica, sociológica, psicológica, etcétera Para ello se establecieron los siguientes criterios metodológicos: (a) la selección de aquellas definiciones que se habían constituido como principales referentes en la elaboración de protocolos de actuación en el marco de las organizaciones laborales y en el diseño de investigaciones de carácter psicosocial sobre la temática, (b) garantizar la presencia de definiciones provenientes del ámbito académico e institucional y (c) incorporar las ópticas internacional, comunitaria y nacional. A partir de estas definiciones hemos podido reconstruir el proceso de conceptualización del fenómeno, que ha ido en paralelo al de su normativización, así como analizar algunos los factores que en él subyacen.

La consideración del acoso sexual laboral como problema social tiene su origen en un análisis sobre la experiencia laboral de mujeres universitarias llevado a cabo en 1974 por feministas norteamericanas de la Universidad de Cornell (Nueva York). En él se identifican pautas comunes y extendidas de la forma en que los hombres se relacionan con las mujeres en la esfera laboral, haciendo incómoda su naturalidad en el empleo (Pernas et al: 2000). Entre estas pautas figuran conductas de naturaleza sexual tales como comentarios, tocamientos o requerimientos sexuales indeseados en general; y también conductas no sexuales, como la infantilización y el paternalismo. Este tipo de comportamientos considerados en otro tiempo como parte inevitable del entorno laboral, comienzan a ser señalados como transgresores de las normas aceptables en las relaciones interpersonales (Stockdale: 1993). Estas feministas evidencian con su análisis y su denuncia social la incongruencia entre un modelo de sociedad que se autoproclama igualitaria y en la que, a su vez, subsisten prácticas que obstaculizan el desarrollo profesional y personal de las mujeres (Ballesteros: 2010).

De esta manera nace la primera definición de acoso sexual, que se refiere a él como una "conducta intrusiva o indeseada de los hombres en la vida de las mujeres". El tipo de conductas englobadas en la definición se suponen presentes en cualquier ámbito de la vida social, además de en el del empleo, y se les añade la etiqueta de "laboral" cuando se producen en dicha esfera. 
La identificación de esta realidad negativa para las mujeres y la aportación de un término con el que poder designarla, es acompañada por un proceso paulatino de denuncia social. Pese a varias resistencias iniciales, se consigue el reconocimiento legal del fenómeno. Estados Unidos vuelve a ser el país pionero, en este caso, en su regulación. Es allí donde se producen los primeros pronunciamientos jurisprudenciales $^{1} \mathrm{y}$ donde se llevan a cabo las primeras construcciones doctrinales, considerándose una problemática que contribuye a la inequidad en las oportunidades de empleo entre mujeres y hombres.

En 1980 la Equal Employment Opportunity Commission de Estados Unidos (EEOC) aporta una segunda definición al considerar que constituyen acoso sexual

las proposiciones sexuales indeseadas, requerimientos para concesiones de tipo sexual y otras conductas fisicas o verbales que constituyen acoso sexual en tres supuestos: 1. su cumplimiento se hace de manera explícita o implícita en términos o como condición para obtener el empleo, 2. su cumplimiento o la negación de su cumplimiento por un individuo es la base para tomar decisiones que afecten el empleo de dicho individuo, 3. tales conductas tienen el propósito o efecto de interferir sin razón en la eficiencia del trabajo de un individuo; o creando un ambiente de trabajo intimidatorio, hostil y ofensivo.

Como se puede observar, esta definición es más amplia que la anterior en relación al sexo de los sujetos que protagonizan el fenómeno, pues deja entrever que tanto hombres como mujeres pueden ser potenciales acosadores/as o acosados/as. Sin embargo, el catálogo de conductas susceptibles de ser catalogadas como acoso sexual laboral es mucho más reducido, ya que se refiere exclusivamente a las conductas sexuales en sentido estricto, como por ejemplo silbidos, miradas lascivas, proposiciones sexuales bajo amenaza, etcétera. Se extraen de esta definición dos posibles tipologías de acoso: el chantaje sexual o acoso quid pro quo y el acoso ambiental. El chantaje sexual alude a aquellas situaciones donde la negativa de una persona ante un requerimiento sexual es utilizada explícita o implícitamente como base para una decisión que afecta al acceso a la formación profesional, al empleo continuado, a la promoción laboral, al salario o a cualquier otra decisión sobre el empleo (puntos 1 y 2). El acoso ambiental es aquel que, sin recurrir al chantaje, genera para quien lo sufre un ambiente humillante, hostil e intimidatorio (punto 3).

La ampliación del contenido de las propuestas conceptuales a los dos sexos y la reducción del tipo de conductas a incluir se visibiliza también en las aportaciones que van proliferando en el ámbito académico. Así, MacKinnon (1979: 23) lo define como "la imposición indeseada de solicitación sexual en el contexto de una relación de poder desigual" y Nicolson et al (1992: 25) como

${ }^{1}$ Jane Aeberhard Hodges (1996) dedica su artículo titulado "Jurisprudencia reciente sobre el acoso sexual en el trabajo" a sistematizar información relevante aportada por diversas sentencias sobre el fenómeno procedentes de diversos países. 
cualquier indeseada e inaceptada insinuación sexual, petición de favores de tipo sexual, contacto físico o de palabra, cuando ese contacto tiene el propósito o efecto de interferir irrazonablemente en el trabajo de un individuo, en su actuación académica o intenta crear un ambiente laboral o académico intimidatorio, hostil u ofensivo.

Ambas definiciones consideran que el acoso puede partir de un hombre o una mujer y dirigirse hacia un hombre o una mujer. $\mathrm{Y}$ ambas entienden que las conductas han de ser sexuales en un sentido estricto.

La ampliación por la parte de los sujetos y la limitación por la parte de las conductas suscita la crítica feminista, materializada en aportaciones académicas de denuncia de las inglesas Wise y Stanley. Estas autoras señalan que el acoso sexual es una "intrusión indeseada y no buscada, por parte de un hombre, en los sentimientos, pensamientos, conductas, espacio, tiempo, energías y cuerpo de una mujer" (Wise y Stanley, 1992: 36). Ellas vuelven a los orígenes de la definición, entendiendo que el hombre es el acosador y la mujer la acosada, y que cualquier conducta intrusiva o indeseada para ella ha de ser denominada acoso sexual (o acoso sexual laboral si se produce en dicho ámbito). También denuncian la apropiación neutral de la cuestión para reivindicar su raíz sexista y alegan que la formulación limitada olvida muchas conductas discriminatorias que no tienen por qué ser sólo de índole sexual, y que su extensión a ambos sexos esconde su naturaleza de fenómeno dirigido especialmente contra las mujeres. Defienden con ello que se trata de una manifestación más de la violencia de género, y que suponer que hombres y mujeres pueden ser personas acosadoras y acosadas es un ejercicio de ocultamiento de la marcada dimensión de género de la problemática.

\subsection{El escenario internacional y europeo}

A partir del referente norteamericano, Naciones Unidas (ONU) y la Organización Internacional del Trabajo (OIT) declaran que el fenómeno constituye un problema de salud e higiene en el trabajo y una discriminación basada en el sexo que obstaculiza la igualdad entre hombres y mujeres. Asimismo, hacen un llamamiento a los gobiernos, empleadores/as, sindicatos y organizaciones no gubernamentales para la erradicación del fenómeno y solicitan la adecuación de la legislación, la adopción de medidas de detección, asistencia y sanción de los casos de acoso, la elaboración de trabajos de investigación y la información sobre las medidas adoptadas.

Encontramos entre su documentación una nueva definición de acoso sexual laboral y algunos ejemplos de conductas susceptibles de ser catalogadas como tal. Concretamente, la Recomendación General N ${ }^{\mathrm{T}} 19$ de la ONU relativa a la violencia contra la mujer de 1992 lo define como

un comportamiento de tono sexual tal como: contactos fisicos e insinuaciones, observaciones de tipo sexual, exhibición de pornografía y exigencias sexuales, verbales o de hecho", aclarando que "es discriminatorio cuando la mujer tiene motivos suficientes 
para creer que su negativa podría causarle problemas en el trabajo, en la contratación o el ascenso inclusive, o cuando crea un medio de trabajo hostil.

En este caso se opta nuevamente por una interpretación restrictiva de las conductas, tal y como propone la EEOC. Sólo aquellas conductas estrictamente sexuales, como las ejemplificadas en la definición, son englobadas bajo el epígrafe de acoso sexual laboral. En cambio, se cita como posibles destinatarias del acoso únicamente a las mujeres, esto es, no se sigue la propuesta de la EEOC relativa a los potenciales sujetos del acoso.

La Unión Europea también toma a Estados Unidos como país referente en la conceptualización y tratamiento del acoso sexual laboral, y recomienda a los Estados miembros la realización de investigaciones en la materia en pro del establecimiento de cauces legislativos unificados con los que combatir el problema (Osborne, 2009). En 1986, el Consejo de Ministros anuncia su voluntad de llevar a cabo una investigación sobre el acoso sexual laboral para analizar la necesidad de su regulación. Esta propuesta se materializa en 1987 en un primer informe titulado "La dignidad de la mujer en el trabajo. Informe sobre el problema del acoso sexual en los Estados miembros de las Comunidades Europeas". El informe, denominado coloquialmente "Rubenstein" en referencia a su principal autor, aporta una definición de acoso similar a la de la Recomendación General No 19 de la ONU (1992). Así, entiende que es acoso sexual laboral

toda conducta verbal o física de naturaleza sexual, cuyo autor sabe o debería saber que es ofensiva para la víctima. Será considerada ilegal: a) cuando el rechazo o la aceptación del tal conducta por la víctima sea utilizada o invocada como amenaza para fundamentar una decisión que afecte a su empleo o condiciones de trabajo, b) cuando la víctima está en condiciones de denunciar que tal conducta ha ocasionado un perjuicio a su ambiente de trabajo.

Aunque en principio la definición recoge una formulación amplia en torno al sexo de los sujetos, se aclara posteriormente que se considera como una discriminación fundada en el sexo y contraria al principio de igualdad de trato entre hombres y mujeres.

A diferencia del caso anterior, la primera normativa comunitaria en la materia, la Resolución de 29 de mayo de 1990 del Consejo de las Comunidades Europeas sobre la protección de la dignidad de la mujer y hombre en el trabajo ${ }^{2}$, no da relevancia al

${ }^{2}$ La Recomendación de la Comisión de las Comunidades Europeas 92/131/CEE, de 27 de noviembre de 1991, relativa a la protección de la dignidad de la mujer y del hombre en el trabajo, aporta una definición a nivel de Derecho Comunitario que reproduce la aportada por esta resolución. 
sexo de los sujetos. Se formula la definición en la línea del EEOC, estableciendo que

la conducta de naturaleza sexual u otros comportamientos basados en el sexo que afectan a la dignidad de la mujer y del hombre en el trabajo, incluida la conducta de superiores y compañeros, constituye una violación intolerable de la dignidad de los trabajadores o aprendices y resulta inaceptable si: a) dicha conducta es indeseada, irrazonable y ofensiva para la persona que es objeto de la misma, b) la negativa o el sometimiento de una persona a dicha conducta por parte de empresarios o trabajadores (incluidos los superiores y los compañeros) se utilizan de forma explícita o implícita como base para una decisión que tenga efectos sobre el acceso de dicha persona a la formación profesional, al empleo, a la continuación del mismo, a los ascensos, al salario o cualesquiera otras decisiones relativas al empleo y/o c) dicha conducta crea un entorno laboral intimidatorio, hostil o humillante para la persona que es objeto de la misma.

Esta definición, además de reflejar explícitamente el posible sexo de las personas implicadas, también hace referencia a su posible jerarquía en la escena laboral.

Finalmente, la Directiva 2002/73/CE del Parlamento Europeo y del Consejo, de 23 de septiembre de 2002, introduce una definición bastante más escueta e indeterminada que las anteriores, calificando de acoso sexual laboral a toda

situación en que se produce un comportamiento no deseado relacionado con el sexo de una persona con el propósito o el efecto de atentar contra la dignidad de la persona y de crear un entorno intimidatorio, hostil, degradante, humillante y ofensivo.

En su preámbulo alienta a los/as empresarios/as y responsables de la formación profesional a tomar medidas preventivas contra el mismo. También la posterior Directiva 2006/54/CE incide en la importancia de la prevención del fenómeno y lo define manteniendo la misma conceptualización.

\subsection{El ámbito nacional}

Por lo que respecta a la normativa que regula el fenómeno en el escenario nacional resulta imprescindible recurrir, en primer lugar, al texto de la Constitución Española de 1978 (CE), ya que en él se aborda el bien jurídico protegido (la libertad sexual) y los derechos conexos transgredidos cuando se producen casos de acoso sexual (la dignidad, la integridad física y moral, el honor, la intimidad, la propia imagen y la igualdad). El Derecho Penal y el Laboral son las principales ramas del Derecho encargadas de velar por la protección de los valores que se pueden perjudicar cuando una persona es acosada sexualmente. A la rama civil tan sólo se recurre cuando entre las personas acosadoras y acosadas no existe una relación contractual o cuando la relación contractual no es laboral.

El Código Penal establece penas de arresto y multa a quienes incurren en este delito. Y es que el acoso sexual laboral es una figura autónoma desde 1995, aunque en su primera regulación solamente condena la tipología de chantaje sexual. Con la reforma aplicada en 1999 se introduce también uno de los múltiples supuestos de la 
tipología de acoso sexual ambiental, el de la solicitud de favores sexuales sin chantaje o amenaza. Se sientan así las bases de la actual definición, que hace referencia a aquél

que solicitare favores de naturaleza sexual para sí o para un tercero, en el ámbito de una relación laboral, continuada o habitual, y con tal comportamiento provocare a la víctima una situación objetiva y gravemente intimidatoria, hostil o humillante (art. 184.1).

Como agravantes se introduce el hecho de prevalerse "de una situación de superioridad laboral" o de anunciar a la víctima de forma tácita o expresa "un mal relacionado con las legítimas expectativas que aquélla pueda tener en el ámbito de la indicada relación" (art. 184.2) y "cuando la víctima sea especialmente vulnerable, por razón de su edad, enfermedad o situación" (art. 184.3).

La última reforma de 2003 únicamente incrementa las sanciones, sin introducir modificación alguna en el concepto. Por su parte, el Estatuto de los Trabajadores (ET) condena el acoso sexual laboral de manera expresa en el artículo 4.2, pero no contempla ninguna definición del fenómeno.

La aprobación en 2007 de la Ley de Igualdad es de suma importancia en esta materia, pues es la primera norma con rango de ley orgánica en la que se dispone un tratamiento para el acoso sexual laboral. Entre las medidas más destacadas está la regulación de la obligación para todas las empresas y para la Administración General del Estado y los Organismos Públicos dependientes de ella ${ }^{3}$ de establecer medidas de intervención social específicas para prevenir el acoso sexual y el acoso por razón de sexo negociadas con los/las representantes de los/las trabajadores/as (arts. 48 y 62$)^{4}$. No podemos dejar de mencionar aquí, en este intento de visibilizar los procesos por los cuales se construye la realidad social, que diversos estudios sobre la negociación colectiva (Vázquez, 1998; Escudero, 2008) y sobre el propio fenó-

${ }^{3}$ Como señala la STC 250/2007, de 17 de diciembre "el deber de toda empresa es el de actuar con diligencia para cumplir con su obligación de protección, siendo responsable no sólo por sus actos u omisiones propios, sino también por los perjuicios causados por sus dependientes". Se ha venido denominando como "teoría del riesgo" a la solicitud de responsabilidades a quién (por acción u omisión) crea las condiciones para que el riesgo se produzca, como es el caso. A modo de ejemplo, la ausencia de protocolo, de medidas preventivas y disciplinarias, es una omisión que crea riesgo.

${ }^{4}$ Los protocolos de actuación frente al acoso sexual laboral se constituyen como la principal medida de intervención social para prevenir el fenómeno, proteger a la persona acosada y sancionar a la acosadora cuando el acoso ya se ha producido. Tal y como señalan Noemí Serrano y otros, hasta la publicación de la Ley de Igualdad en 2007, entre un 70\% y un $80 \%$ de los Convenios Colectivos ignoraban las conductas de acoso sexual (Serrano et al, 2009). 
meno del acoso sexual laboral (Calle et al, 1988; Emer Estudios, 1994; Pernas et al, 2000; Ibáñez et al, 2007) han insistido reiteradamente en la necesidad de establecer protocolos de actuación contra el acoso sexual laboral en el seno de las organizaciones laborales.

Como no podía ser de otra manera, esta Ley también hace una contribución a la definición del fenómeno, señalando que

constituye acoso sexual cualquier comportamiento, verbal o fisico, de naturaleza sexual que tenga el propósito o produzca el efecto de atentar contra la dignidad de una persona, en particular cuando se crea un entorno intimidatorio, degradante u ofensivo (art. 7.1).

Por último, y acudiendo a la doctrina, una de las definiciones más relevantes sobre acoso sexual laboral, la de Salvador del Rey Guanter (1993), entiende como tal a toda

conducta de naturaleza sexual, desarrollada en el ámbito de organización y dirección del empresario que el sujeto activo sabe o debe saber que es indeseada por el trabajador y cuya posición ante la misma determina una decisión afectante al empleo o a las condiciones de trabajo de éste o que, en todo caso, tiene como objetivo o como consecuencia crearle un entorno laboral ofensivo, hostil o intimidatorio.

En conclusión, desde el momento en el que se inició el proceso de identificación y caracterización del acoso sexual laboral en la década de los setenta, los principales conceptos de referencia han sufrido varias modificaciones en su contenido. Aún a día de hoy no podemos afirmar que exista un consenso generalizado en torno a la delimitación de lo que es y lo que no es el acoso sexual laboral. La inexistencia de una definición única y clara genera dificultades de partida tanto para la intervención social, como para la investigación en la materia, como se verá en el siguiente epígrafe.

\section{Una deconstrucción del concepto de acoso sexual laboral: reflexiones sobre su influencia en el diseño de investigaciones e intervenciones sociales}

\subsection{La importancia del concepto de partida para la investigación y la inter- vención social}

A la hora de investigar una problemática o de intervenir sobre ella tenemos que comenzar por su delimitación, algo que habitualmente hacemos a partir del empleo de conceptos. Como señalan Rodríguez y Luengo (2003: 62), la reflexión sobre el alcance y limitaciones de los conceptos "constituye un mecanismo para la mejora de estos instrumentos básicos del discurso científico". En el caso de la temática que nos ocupa se puede afirmar sin dudas que no se pueden diseñar medidas de intervención e investigaciones para identificar, prevenir, medir y erradicar el acoso 
sexual laboral si no tenemos claro de qué hablamos cuando nos referimos a él, lo que nos lleva necesariamente a la revisión del concepto.

En la investigación social la delimitación clara y rigurosa de lo que se va a considerar como objeto de estudio tiene una importancia decisiva respecto al valor del estudio en cuestión. Las definiciones que toman como referencia las investigaciones realizadas son en ocasiones divergentes. Este hecho genera ya diferencias de partida. Si no existe un planteamiento común sobre el contenido del fenómeno, éste no se medirá de la misma manera, las cifras serán dispares y los resultados no serán comparables. No obstante, lo fundamental es conocer en cada momento de qué concepción de acoso sexual laboral parten los/las diferentes autores/as y qué realidad miden los datos aportados. En este sentido, y desde la perspectiva del interés por el análisis de la construcción social de la realidad, nos preocupa más la reflexión sobre lo que cada sujeto considera conocimiento que la discusión sobre la validez o universalidad del mismo.

Por el lado de la intervención social, tanto para elaborar protocolos de actuación como para diseñar otro tipo de medidas, es totalmente necesario rodear al fenómeno de una frontera que lo diferencie de otros usos y costumbres sociales no transgresoras, como lo son las pautas que rigen el ámbito del cortejo. La posibilidad de obtener una definición estándar facilitaría la labor de dar a conocer a la sociedad en general, y al entorno laboral en particular, qué situaciones son constitutivas de acoso y, por lo tanto, sancionables. Sin embargo no podemos olvidar que la realidad es compleja e imposible de atrapar en un único concepto y que no hay una realidad universal, sino distintas realidades singulares.

En cualquier caso, toda medida de intervención social en materia de acoso sexual laboral tiene que partir de una definición muy clara que explique detalladamente quiénes son los sujetos potencialmente acosadores y acosados, qué conductas pueden considerarse de acoso sexual y cuál ha de ser la percepción de quien las recibe para que lleven dicha etiqueta. Esta definición de partida va a condicionar posteriores medidas formativas en las que se desarrollen esos contenidos y de ella van a depender las sanciones que se impongan a la persona acosadora. Especialmente importante es clarificar el concepto en protocolos de actuación que unifican fenómenos tan dispares como el acoso sexual, el mobbing y el acoso por razón de sexo.

Las principales conceptualizaciones de acoso sexual laboral estudiadas en el apartado anterior nos dan idea de la variedad de formas de entender y abordar esta problemática. Asimismo, cada apuesta por una caracterización u otra del fenómeno tiene importantes implicaciones metodológicas que condicionarían cualquier intento de medir la incidencia del acoso sexual en la población trabajadora o el diseño de medidas de intervención para prevenir y/o erradicar el fenómeno.

A la vista de las definiciones revisadas, se podría afirmar que las principales divergencias existentes tienen que ver con las siguientes cuestiones: 
- Si las personas potencialmente acosadas son únicamente las mujeres o también lo pueden ser los hombres.

- Si es acoso sexual laboral solamente el que proviene de superiores jerárquicos o también el que proviene de compañeros/as o clientes.

- Si es acoso sexual laboral tan sólo el experimentado por personas integradas en la plantilla de una organización o también el vivenciado por personas en vías de acceso al empleo.

- Si es acoso sexual laboral toda conducta intrusiva en la esfera laboral o sólo las conductas estrictamente sexuales.

- Si son acoso sexual laboral sólo las conductas de chantaje sexual o también las conductas de acoso ambiental.

- Si son acoso sexual laboral las conductas ofensivas y/o las irrazonables, las indeseadas, las no buscadas y/o las inaceptadas.

- Si es necesario que la persona acosada manifieste tácita o abiertamente su desagrado y oposición.

\subsection{Un análisis de los principales elementos conceptuales}

Con el fin de delimitar el objeto de estudio de nuestro interés, el acoso sexual laboral, hemos partido de algunas definiciones de referencia. Concretamente, hemos seleccionado aquellas tomadas como referentes en los estudios españoles y en la mayor parte de los protocolos de actuación de organizaciones públicas y privadas, dado que una de las principales pretensiones del artículo es aportar reflexiones para el diseño de investigaciones e intervenciones sociales. Otro criterio metodológico tenido en cuenta para la elección de conceptos ha sido la representación de definiciones tanto académicas como institucionales, de nivel internacional, comunitario y nacional.

Analizados en detalle, los conceptos revisados en el epígrafe anterior presentan aspectos comunes y también ciertas diferencias en torno a su contenido. La Figura 1 contiene la relación de los elementos más habituales encontrados en las definiciones estudiadas, con indicación de sus posibles dimensiones. Hemos identificado tres elementos fundamentales, los sujetos, las conductas y la percepción de la persona acosada. Todos ellos se analizan a continuación. 


\section{Figura 1}

\section{Elementos de la estructura conceptual del acoso sexual laboral}

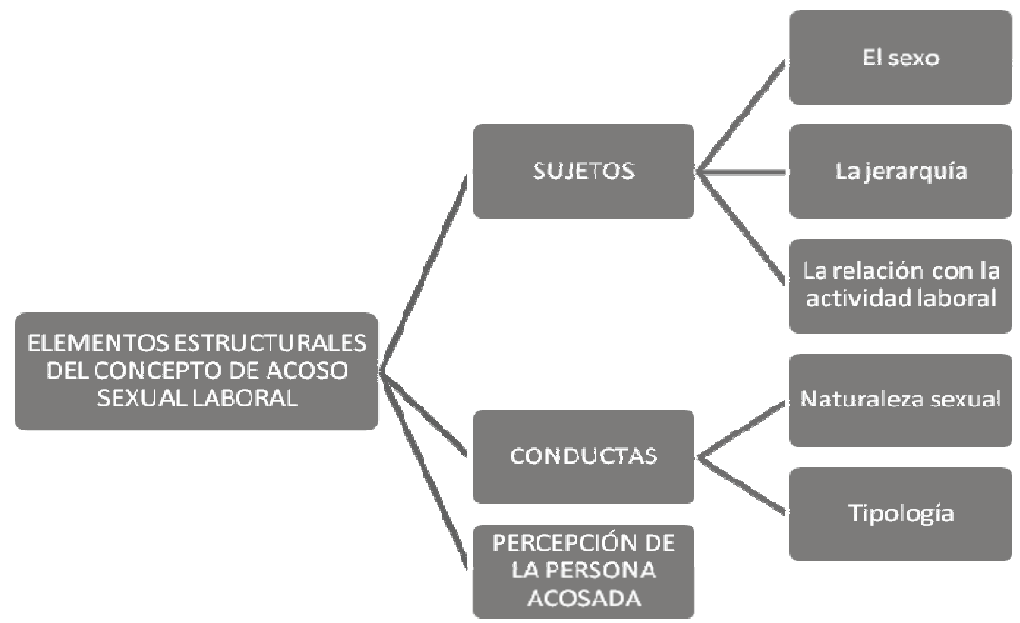

Fuente: Elaboración propia.

\section{Los sujetos}

Todas las definiciones de acoso sexual laboral intentan caracterizar a las personas potencialmente acosadoras y/o acosadas. Se trata implícita o explícitamente del sexo, la jerarquía entre ambos sujetos y la relación con la actividad laboral de la persona acosada.

\section{1.a El sexo}

Aunque algunas de las definiciones manejadas señalan únicamente que las personas destinatarias del acoso sexual laboral son las mujeres ${ }^{5}$, la mayoría consideran, bien sea de manera explícita ${ }^{6}$ o implícita, que tanto los varones como las mujeres pueden sufrir acoso. Se puede decir así, siguiendo la terminología de Wise y Stanley (1992), que la mayor parte de las definiciones califican el fenómeno de un modo "unisexual", en el sentido de que personas de ambos sexos pueden verse afectadas por él.

Respecto al sexo esperado de la persona acosadora sólo dos definiciones se posicionan considerando que es el masculino ${ }^{7}$. El resto, de forma tácita, se refieren a ambos sexos como potenciales acosadores. Pero pese a no incluirlo necesariamente en la definición, la mayor parte de la producción científica sobre el acoso sexual laboral

${ }^{5}$ Universidad de Cornell: 1974; Informe Rubenstein: 1987; Recomendación General 19: 1992 y Wise y Stanley: 1992.

${ }^{6}$ Sólo la Resolución 29 de mayo de 1990 del Consejo de las Comunidades Europeas contiene abiertamente la referencia a mujeres y hombres.

${ }^{7}$ Son las de Universidad de Cornell (1974) y Wise y Stanley (1992). 
lo vincula a un ejercicio de poder de género. Este poder es concebido como resultado de un poder simbólico, un imaginario patriarcal que conduce a la valoración de la mujer por su papel sexual en detrimento del profesional ejercido gracias a la existencia de un poder real y referido a la desigualdad que sufren las mujeres en el acceso y permanencia en el mercado laboral. También la tradición jurídica europea tiene en consideración la dimensión de género de la problemática, que se conecta con el principio constitucional de igualdad entre los sexos y es tratada esencialmente desde la óptica de la discriminación por razón de sexo.

Obviamente ambas posturas no tienen por qué ser excluyentes, sobre todo si tenemos en cuenta que se trata de un concepto de marcado carácter jurídico. No podemos obviar que el bien jurídico protegido es la sexualidad del/la trabajador/a en sentido estricto, y no como género masculino o femenino. Por lo tanto, desde el punto de vista de la protección en la elaboración de protocolos, ambos sexos han de ser considerados como potenciales destinatarios de episodios de acoso sexual laboral. De la misma forma, a la hora de investigar la incidencia o prevalencia del acoso sexual laboral en un contexto determinado, perderíamos una interesante información si excluyéramos a la población masculina del universo $\mathrm{y}$, por lo tanto, de la muestra. Evidentemente, todo depende de los objetivos de cada estudio y, salvo como apunte general, no se puede ni debe establecer reglas fijas al respecto. Eso no exime, de forma complementaria y ya desde el punto de vista teórico - empírico, de indagar en las sustanciales diferencias entre sexos que se manifiestan en su incidencia, casuística y significación. Como señalan Wise y Stanley (1992), hay que evitar la neutralización del fenómeno evidenciando que se trata principalmente de una manifestación más de la violencia contra las mujeres.

\section{1.b. La jerarquía}

Sólo una de las definiciones revisadas hace referencia explícita a la dimensión jerárquica, indicando que se incluye la conducta de superiores y compañeros/as ${ }^{8}$. En otros casos o bien no hay alusiones a este aspecto o la referencia es implícita, es decir, alude a la posibilidad de que la persona acosadora utilice un poder para tomar decisiones que afecten al empleo de la acosada y señala que éste le puede generar un ambiente intimidatorio y hostil. En el primer caso, cuando hablamos de la toma de decisiones que afectan al empleo, se presupone que el principal poder que otorga tales privilegios es el poder jerárquico. Pero ésta no es una condición indispensable, ya que el poder de influencia, por ejemplo, también puede contribuir a esos fines. En el segundo caso, cuando hablamos de la generación de un entorno hostil, se presupone que no es necesario ser superior en el escalafón laboral para intimidar a un/a supe-

\footnotetext{
${ }^{8}$ Es la de la Resolución de 29 de mayo de 1990 del Consejo de las Comunidades Europeas.

${ }^{9}$ Está ausente en Universidad de Cornell (1974) y Wise y Stanley (1992).
} 
rior/a o compañero/a. No obstante, se sobreentiende que apoyan la tesis de que tanto compañeros/as como superiores pueden ser acosadores/as y acosados/as.

El consenso en relación con este asunto es bastante generalizado. Si en un primer momento tenía mayor protagonismo un discurso centrado en la noción unidimensional de poder, la del poder jerárquico, posteriormente esta noción se diluye y se considera que no es una condición indispensable para poder acosar sexualmente a alguien. Aunque los superiores jerárquicos continúen siendo los principales acosadores en el imaginario colectivo, desde el punto de vista teórico y legal se reconoce la existencia de otras formas de ejercer el poder además del poder jerárquico. Este es el caso del poder de género y/o el poder de influencia sobre el entorno. Y es que, incluso sin ostentar ningún tipo de poder, una persona puede acosar sexualmente a otra generando un ambiente intimidatorio y hostil. Así, los/as compañeros/as pueden ejercer el acoso, y también lo pueden hacer los/as clientes. La producción científica sobre acoso sexual laboral considera que los/as clientes son también potenciales acosadores/as de los/las profesionales, aunque no viceversa. Un ejemplo frecuente lo encontramos en el trato discriminatorio y de acoso sexual que las enfermeras reciben de algunos pacientes, como ilustra un estudio realizado en Andalucía y Cataluña (Alemany et al: 2000).

Ninguna definición recoge explícitamente esta posibilidad, aunque implícitamente cabe en cualquiera de ellas. Pero el hecho de que esté implícito no significa necesariamente que los/as trabajadores/as de una determinada organización laboral no especializados/as en la materia sean conscientes de estos supuestos. Por ello conviene evidenciarlo de la forma más clara posible en la definición de acoso sexual y, por supuesto, en los contenidos formativos. En las investigaciones, en cambio, se suele tener en cuenta la verticalidad y horizontalidad del acoso en todo momento.

\section{1.c. La relación con la actividad laboral}

Con respecto a esta dimensión existe una acusada ausencia de posicionamientos manifiestos, si bien algunas definiciones ${ }^{10}$ engloban a las personas en vías de acceso al empleo además de a los/las trabajadores/as integrados/as en la plantilla. Las personas que se encuentran como becarias de prácticas pueden ser acosadas sexualmente al igual que cualquier trabajador/a integrado/a en la plantilla, porque también participan de la dinámica organizacional y pueden incluso ser más vulnerables y menos creíbles que quienes tienen mayor estabilidad en la organización y/o llevan más tiempo dentro de la misma. Olvidar a estas personas sería negar una parte importante del alcance del fenómeno en el caso de las investigaciones, y una adecuada protección en el caso de los protocolos.

${ }^{10}$ Las de EECO (1980), Informe Rubenstein (1987), Resolución de 29 de marzo (1990), Nicolson y Ussher (1992), Del Rey (1993) y Código Penal (2003). 


\section{Las conductas}

Las definiciones de acoso sexual laboral estudiadas intentan caracterizar las conductas que lo constituyen fundamentalmente de dos maneras. La primera hace referencia a las posibles interpretaciones sobre la naturaleza "sexual" de estas conductas. Una es la interpretación estricta, que entiende por tales únicamente a aquellas relativas al sexo (insinuaciones, tocamientos, etc.). Otra es la interpretación amplia, que amplía la visión a cualquier conducta intrusiva e indeseada practicada contra los sujetos de sexo femenino. La segunda cuestión alude al reconocimiento de la doble vertiente del acoso sexual: el acoso ambiental y el chantaje sexual.

\section{2.a. Naturaleza sexual}

La naturaleza sexual de las conductas es entendida de forma restrictiva por la gran mayoría de las definiciones, que limitan el acoso sexual laboral a las conductas que están relacionadas con el sexo (miradas, insinuaciones, tocamientos...). La formulación amplia está presente únicamente en los inicios de la formulación del fenómeno por parte de las feministas norteamericanas (Universidad de Cornell: 1974) y en la definición de las académicas Wise y Stanley (1992), que trataron de rescatar el sentido originario. El sentido amplio amplía su consideración a numerosas situaciones que se producen habitualmente, tanto en el entorno laboral como fuera de él, y que acarrean consecuencias negativas para las mujeres. Estas situaciones no deben quedar invisibilizadas y, una vez identificadas, tienen que ser designadas para poder hacerse visibles. Pero dotar al concepto de acoso sexual laboral de tanta amplitud puede no ser operativo de cara a su judicialización, comprensión y medición, ya que engloba bajo una misma denominación situaciones muy divergentes. Por otra parte, es posible que dificulte el deseable consenso social en la definición del concepto. Una definición es aceptada en la medida que parece "adecuada" y "lógica". La excesiva amplitud puede ser considerada socialmente como una "exageración". El optar por una conceptualización más precisa y abierta a la aceptación no significa negar otras realidades que constituyen manifestaciones del sexismo.

La delimitación de conductas que pueden catalogarse como tal no es una tarea sencilla, ya que el hecho de que constituyan acoso está más ligado a la percepción de la persona receptora que a la propia conducta en sí. Aún así, también aparece recurrentemente en diversos estudios sobre esta temática, que utilizan un catálogo de conductas para preguntar por la posible vivencia del acoso a las personas de la muestra. De esta forma diferencian las cifras del acoso declarado (porcentaje de personas que declaran haber sido objeto de acoso) y del acoso técnico (porcentaje de personas que manifiestan haber experimentado alguna situación en el marco de las conductas sexuales incluidas en los catálogos, independientemente de que lo etiqueten como acoso sexual), calculando así el diferencial entre ambas. 
Algunas investigaciones incluso clasifican las conductas contenidas en el catálogo atendiendo al criterio de gravedad. Por su parte, la Sentencia del Tribunal Constitucional 224/1999, de 13 de diciembre ${ }^{11}$, para hablar de acoso sexual laboral, exige que "la conducta sea lo suficientemente grave, por su intensidad, reiteración y efectos sobre la salud mental de la trabajadora", requisito que desde nuestro punto de vista no obliga a que toda conducta sexual haya de reiterarse, sino que puede darse una sola conducta de acoso grave, en cuyo caso no es necesaria la persistencia. La importancia de la percepción en el establecimiento del grado de gravedad hace que sea recomendable optar por criterios generales que introduzcan supuestos objetivos ${ }^{12}$.

\section{2.b. Tipología}

La tipología de las conductas de acoso está muy unida a la dimensión de la jerarquía, ya que parece como si el chantaje sexual sólo pudiera ser llevado a cabo por los/as superiores y el acoso ambiental por los/las compañeros/as. Realmente, el chantaje sexual se genera cuando la persona tiene poder para generarlo, independientemente de la jerarquía; y el acoso ambiental lo pueden efectuar tanto superiores como compañeros/as, e incluso clientes.

Igual que se tiende a pensar que el acoso sexual laboral es generalmente ejercido por un/a jefe/a, también se piensa que se suele ejercer en la modalidad de chantaje sexual. De hecho, en la primera etapa de regulación del fenómeno sólo se considera como acoso al chantaje sexual ${ }^{13}$ y sólo con el paso del tiempo se termina por reconocer de forma generalizada la existencia del acoso ambiental.

De forma más o menos explícita, ambas tipologías son reconocidas por las diferentes definiciones estudiadas. Esta forma amplia de entender el fenómeno es necesaria para evidenciar que el acoso sexual no se genera únicamente en los ámbitos en los que interviene el poder jerárquico, sino que está presente en otros ámbitos de la vida social. No sólo conforman el acoso las conductas más aparentemente graves. Además, si entendiéramos que los/las compañeros/as y clientes no tienen poder para cometerlo, estaríamos negando una parte sustancial del generado en la propia esfera laboral. Ambas tipologías han de ser reflejadas tanto en la investigación como en la intervención social.

${ }^{11}$ La STC 224/1999, de 13 de diciembre, es la primera dictada en materia de acoso sexual por el Alto Tribunal.

${ }^{12}$ Por ejemplo la naturaleza de la conducta (un chantaje sexual, un acorralamiento...), la reincidencia de la persona acosadora, el acoso sexual dirigido a más de una persona.

${ }^{13}$ Un ejemplo es el Código Penal español, que hasta 1999 no reconoce la punición de uno de los supuestos de acoso sexual ambiental. 


\section{La percepción de la persona acosada}

En todas las definiciones de acoso sexual laboral analizadas se aborda el tema de qué supone dicha conducta sexual para la persona acosada y cómo la recibe o se posiciona frente a ella. Los calificativos al respecto son numerosos y diferentes: indeseada, ofensiva, irrazonable, inaceptada o no buscada. Aunque estos son calificativos para las conductas, los consideramos en un apartado diferente porque son fruto de la percepción de que ellas tiene la persona acosada. Es decir, una conducta determinada no es ofensiva intrínsecamente, lo es en la medida que genera molestia para quien la recibe. Posiblemente este sea uno de los criterios más importantes para delimitar el fenómeno.

La etiqueta de "ofensiva", una de las más utilizadas, se encuentra en casi todas las definiciones ${ }^{14}$. En este sentido, es perfectamente entendible que una conducta sexual llegue a ser considerada como acoso cuando es humillante y genere ofensa para la persona que la recibe. El calificativo de "irrazonable", que sólo es utilizado por la definición de la Resolución de 29 de mayo de 1990 del Consejo de las Comunidades Europeas, recalca la idea de que la acción carece de razón, de justicia y de rectitud o derecho para ser ejecutada. En consecuencia, lo irrazonable de una conducta puede ser el resultado de la ofensa que genera. Este calificativo no aporta mucha información adicional, pero es adecuado como complemento del de ofensiva.

Algunas de las definiciones estudiadas exigen que las conductas sean "no buscadas" 15 y "no deseadas"16. Es evidente que no todas las atenciones sexuales no solicitadas tienen por qué constituir acoso sexual. Además, la utilización de estos términos puede introducir el peligro de propiciar errores de atribución, culpando a la persona acosada de lo sucedido en los casos en los que su carácter es abierto, desinhibido, o su vestimenta provocativa. Incluso cuando una conducta pudiera ser en determinadas ocasiones realmente buscada y deseada, la simple negativa posterior debe inhibir a la persona emisora de futuras manifestaciones. Por ambas razones consideramos que estos calificativos son ambiguos e inadecuados para definir la percepción de la persona acosada, tanto para ser utilizados para realizar una pregunta en una encuesta o entrevista sobre la vivencia de acoso sexual, como para ser considerados como condición en la caracterización y penalización de las conductas sexuales.

La "no aceptación", es decir, la necesidad de manifestar implícitamente (dar a entender) o explícitamente (decir abiertamente) el rechazo ante las conductas sexuales, no es una cuestión que se evidencie en la mayor parte de las definiciones ${ }^{17}$. Una

${ }^{14}$ Salvo en las de la Universidad de Cornell (1974), MacKinnon (1979) y Wise y Stanley (1992).

${ }_{16}^{15}$ Este es el caso de la definición de Wise y Stanley (1992).

${ }^{16}$ Así se constata en todas salvo en la definición del Informe Rubenstein (1987), la Recomendación General 19 (1992), Del Rey (1993), el Código Penal (2003) y la Ley de Igualdad (2007).

${ }^{17}$ Ésto sólo lo recoge la definición de Nicolson et al (1992). 
conducta es aceptada cuando se recibe voluntariamente o sin oposición. Mostrar oposición ante conductas que resultan ofensivas se torna entonces necesario para poder proceder a su penalización. Si no se da a conocer al/la interlocutor/a nuestra forma de valorar su conducta, estamos omitiendo información relevante para que pueda ser catalogada como un uso o como un abuso. Pero la no aceptación tampoco es un criterio totalmente decisivo, porque puede haber muchos casos en los que las conductas sean ofensivas pero aceptadas por el miedo a perder el empleo o prerrogativas en el mismo, a causar conflicto en la organización laboral o a no ser creído/a por la ausencia de pruebas. Y también existen determinadas conductas que, sin necesidad de ser desaprobadas, pueden ser catalogadas sin lugar a confusión como acoso sexual. No son comparables en ese sentido conductas como solicitar repetidas veces una cita y realizar presiones para obtener favores sexuales a cambio de mejoras laborales.

En ocasiones (salvo en los casos de presión y/o amenaza), la persona que realiza la conducta puede tratar de una forma más o menos acertada de acercarse y/o "ligar" con la persona que la recibe, y precisa de una aclaración en sentido negativo para que la prolongación de su conducta pueda ser objeto de penalización. Se puede identificar como una manifestación de acoso cualquier aproximación sexual que carezca de estilo o que sea irrespetuosa, pero no es lo mismo observar que quien acosa se manifiesta a veces como un/a zafio/a irrespetuoso/a que afirmar que quien se manifiesta zafia e irrespetuosamente en cuestiones de aproximación sexual es una persona acosadora. Según Martín y Martín (1999), la primera solicitud podrá ser considerada como una propuesta, que será de recibo si la persona solicitada se aviene y que no deberá de repetirse en el caso de que la persona destinataria rechace ese avance. Mejías (1991: 64) señala al respecto que

la mera atención sexual puede convertirse en acoso si continúa una vez que la persona objeto de la misma ha dado claras muestras de rechazo. Ello distingue el acoso sexual de las aproximaciones personales libremente aceptadas basadas, por tanto, en el consentimiento тиtиo.

Pero hay que considerar que la reacción airada de la víctima, su incomodidad y desagrado ante los requerimientos, son indicios racionales de que tal conducta es molesta. Desde el punto de vista de los protocolos, no sería exigible que reaccione de inmediato y con especial contundencia, sino que bastaría una señal del carácter no querido de tal conducta para deshacer cualquier equívoco o ambigüedad al respecto. Desde el punto de vista de la investigación, no es tan importante la comunicación o exteriorización de la ofensa, aunque añade información interesante a los estudios si se pregunta por la reacción al sufrir el acoso sexual.

El Cuadro 1 resume el posicionamiento de las definiciones de acoso sexual laboral manejadas frente a los elementos conceptuales identificados. 


\section{Cuadro 1}

Presencia de los principales elementos conceptuales en las definiciones de acoso sexual laboral manejadas y su posicionamiento al respecto.

\begin{tabular}{|c|c|c|c|c|c|c|c|}
\hline Ámbito & Definnición & Sexo & Jerarquía & $\begin{array}{c}\text { Relación con } \\
\text { actividad } \\
\text { laboral }\end{array}$ & $\begin{array}{c}\text { Naturaleza } \\
\text { sexual }\end{array}$ & Tipología & $\begin{array}{c}\text { Percepción } \\
\text { persona } \\
\text { acosada }\end{array}$ \\
\hline \multirow{5}{*}{ Académico } & $\begin{array}{l}1974 \text { Univ. } \\
\text { Cornell }\end{array}$ & $\mathrm{M}$ & & & Amplio & & Indeseada \\
\hline & $\begin{array}{c}1979 \\
\text { MacKinnon }\end{array}$ & $\mathrm{H} / \mathrm{M}$ & $\begin{array}{l}\text { Implícito } \\
\text { No limitado }\end{array}$ & & Restringido & & Indeseada \\
\hline & $\begin{array}{l}1992 \\
\text { Nicolson, } \\
\text { Ussher y } \\
\text { Compling }\end{array}$ & $\mathrm{H} / \mathrm{M}$ & $\begin{array}{l}\text { Implícito } \\
\text { No limitado }\end{array}$ & $\begin{array}{l}\text { Trabajador/a } \\
\text { potencial } \\
\text { trabajador/a }\end{array}$ & Restringido & $\begin{array}{l}\text { Chantaje } \\
\text { acoso } \\
\text { ambiental }\end{array}$ & $\begin{array}{l}\text { Indeseada } \\
\text { Inaceptada } \\
\text { Ofensiva }\end{array}$ \\
\hline & $\begin{array}{l}1992 \text { Wise y } \\
\text { Stanley }\end{array}$ & $\mathrm{M}$ & & & Amplio & & $\begin{array}{l}\text { Indeseada } \\
\text { No buscada }\end{array}$ \\
\hline & 1993 Del Rey & $\mathrm{H} / \mathrm{M}$ & $\begin{array}{l}\text { Implícito } \\
\text { No limitado }\end{array}$ & $\begin{array}{l}\text { Trabajador/a } \\
\text { potencial } \\
\text { trabajador/a }\end{array}$ & Restringido & $\begin{array}{l}\text { Chantaje } \\
\text { acoso } \\
\text { ambiental }\end{array}$ & Indeseada \\
\hline \multirow{7}{*}{ Institucional } & 1980 EECO & $\mathrm{H} / \mathrm{M}$ & $\begin{array}{l}\text { Implícito } \\
\text { No limitado }\end{array}$ & $\begin{array}{l}\text { Trabajador/a } \\
\text { potencial } \\
\text { trabajador/a }\end{array}$ & Restringido & $\begin{array}{l}\text { Chantaje } \\
\text { acoso } \\
\text { ambiental }\end{array}$ & $\begin{array}{l}\text { Indeseada } \\
\text { Ofensiva }\end{array}$ \\
\hline & $\begin{array}{l}1987 \text { Informe } \\
\text { Rubenstein }\end{array}$ & $\mathrm{M}$ & $\begin{array}{l}\text { Implícito } \\
\text { No limitado }\end{array}$ & Trabajadores/as & & $\begin{array}{l}\text { Chantaje } \\
\text { acoso } \\
\text { ambiental }\end{array}$ & Ofensiva \\
\hline & $\begin{array}{l}\text { Resolución } 29 \\
\text { mayo } 1990 \\
\text { Consejo } \\
\text { Comunidades } \\
\text { Europeas }\end{array}$ & $\mathrm{H} / \mathrm{M}$ & $\begin{array}{l}\text { Explícito } \\
\text { superiores y } \\
\text { compañe- } \\
\text { ros/as }\end{array}$ & $\begin{array}{l}\text { Trabajadora } \\
\text { potencial } \\
\text { trabajadora }\end{array}$ & Restringido & $\begin{array}{l}\text { Chantaje } \\
\text { acoso } \\
\text { ambiental }\end{array}$ & $\begin{array}{l}\text { Indeseada } \\
\text { Ofensiva } \\
\text { Irrazonable }\end{array}$ \\
\hline & $\begin{array}{l}1992 \\
\text { Recomenda- } \\
\text { ción General } \\
19 \text { ONU }\end{array}$ & $\mathrm{M}$ & $\begin{array}{l}\text { Implícito } \\
\text { No limitado }\end{array}$ & $\begin{array}{l}\text { Trabajador/a } \\
\text { potencial } \\
\text { trabajador/a }\end{array}$ & Restringido & $\begin{array}{l}\text { Chantaje } \\
\text { acoso } \\
\text { ambiental }\end{array}$ & $\begin{array}{l}\text { Humillante } \\
\text { (ofensiva) }\end{array}$ \\
\hline & $\begin{array}{c}\text { Directiva } \\
\text { 2002/73/CE }\end{array}$ & $\mathrm{H} / \mathrm{M}$ & $\begin{array}{l}\text { Implícito } \\
\text { No limitado }\end{array}$ & & Restringido & $\begin{array}{l}\text { Chantaje } \\
\text { acoso } \\
\text { ambiental }\end{array}$ & $\begin{array}{l}\text { Indeseada } \\
\text { Ofensiva }\end{array}$ \\
\hline & $\begin{array}{l}2003 \text { Art. } 184 \\
\text { Código Penal }\end{array}$ & $\mathrm{H} / \mathrm{M}$ & $\begin{array}{l}\text { Implícito } \\
\text { No limitado }\end{array}$ & $\begin{array}{l}\text { Trabajador/a } \\
\text { potencial } \\
\text { trabajador/a }\end{array}$ & Restringido & $\begin{array}{l}\text { Chantaje } \\
\text { acoso } \\
\text { ambiental }\end{array}$ & $\begin{array}{l}\text { Humillante } \\
\text { (ofensiva) }\end{array}$ \\
\hline & $\begin{array}{l}2007 \text { Ley de } \\
\text { Igualdad }\end{array}$ & $\mathrm{H} / \mathrm{M}$ & $\begin{array}{l}\text { Implícito } \\
\text { No limitado }\end{array}$ & & Restringido & $\begin{array}{l}\text { Chantaje } \\
\text { acoso } \\
\text { ambiental }\end{array}$ & Ofensiva \\
\hline
\end{tabular}

Fuente: Elaboración propia.

\section{Orientaciones para la investigación y la intervención social}

Tras revisar el contenido de una serie de aportaciones conceptuales relevantes, se aprecia que, a pesar de existir diferencias entre ellas, contienen una estructura similar a la hora de comprender el acoso sexual laboral. En una labor de deconstrucción del concepto, hemos identificado tres principales elementos de análisis a tener en cuenta: los sujetos (sexo, jerarquía y relación con la actividad laboral), las conductas (naturaleza y tipología) y la percepción de la persona acosada.

En relación a estos elementos se abre toda una amplia gama de interrogantes con implicaciones de cara al análisis de esta realidad social que se han ido abordando y analizando a lo largo del artículo. ¿Únicamente pueden ser acosadas sexualmente 
las mujeres? ¿o también lo pueden ser los hombres? ¿Es acoso sexual laboral sólo aquel que proviene de superiores jerárquicos? ¿o también el que proviene de compañeros/as y/o clientes? ¿Es acoso sexual laboral tan sólo el experimentado por personas integradas en la plantilla de una organización laboral? ¿o también el vivenciado por personas en vías de acceso al empleo? ¿Es acoso sexual laboral toda conducta intrusiva para las mujeres en la esfera laboral? ¿o lo ceñimos a las conductas estrictamente sexuales? ¿Son acoso sexual laboral sólo las conductas de chantaje sexual? ¿o también las conductas de acoso ambiental? ¿Constituyen acoso sexual laboral a las conductas sexuales ofensivas? ¿y las irrazonables, las no deseadas o no buscadas y/o las inaceptadas?

En definitiva, a la vista de la información analizada podemos concluir que el acoso sexual laboral es un fenómeno que ha ido considerándose progresivamente como un problema social emergente. Dicha catalogación viene acompañada de un gran interés por establecer el tratamiento más adecuado para su erradicación. De esta labor se han encargado la OIT, la ONU, el Derecho Comunitario y diferentes ramas del Derecho español. De forma paralela a su normativización, se han venido aportando diversas definiciones para designarlo, sin llegar a conseguir entre ellas un consenso generalizado. Esta limitación puede condicionar el diseño tanto de las medidas de intervención social frente al fenómeno, como de los trabajos de investigación de los cuáles es objeto de estudio.

Por una parte, la elaboración de protocolos de actuación o el diseño de cualquier otra medida de intervención social requiere de una definición clara de partida. De esta forma se puede establecer la frontera entre el uso y el abuso, entre el acoso sexual y otras prácticas sociales no transgresoras. Al hilo de esta cuestión, se impone la necesidad de que en los convenios colectivos en general, y en los protocolos de cada organización laboral en particular, se clarifique qué se entiende exactamente por acoso sexual laboral, ya que sólo así se podrá estipular nítidamente después qué tipo de conductas son constitutivas de este delito, cuál va a ser el procedimiento a seguir para prevenir y para abordar el problema y cuál va a ser, en su caso, el régimen sancionador.

Resulta importante hacer notar que las diferentes conceptualizaciones del acoso sexual en el trabajo pueden llevar a tratamientos muy distintos de las víctimas y los responsables. En el caso español se constata una creciente sensibilización por la consideración en clave de género del problema del acoso sexual laboral, sin duda debido a la importante influencia de la legislación comunitaria de igualdad de oportunidades en materia de empleo en la consideración del fenómeno. No obstante, si queremos asegurarnos de que hay avances significativos en la erradicación del citado problema social habrá que seguir perfilando cómo éste se manifiesta en los complejos y cambiantes contextos y relaciones laborales de cada momento.

Por su parte, si bien la estandarización de la definición no es un requisito indispensable ni para la intervención social ni para la investigación, la delimitación clara y rigurosa del objeto de estudio en una investigación tiene una importancia decisiva respecto al valor del estudio en cuestión, esta estandarización facilitaría la labor de dar a conocer a la sociedad en general, y al entorno laboral en particular, las situa- 
ciones que son constitutivas de acoso y, por ende, sancionadas. Contribuiría a aunar los criterios de medición de esta realidad problemática y revertiría en la comparabilidad de los resultados obtenidos en cada estudio.

No obstante, no es tan importante el poder comparar cifras como el saber en cada momento qué realidad miden en cada caso los datos aportados. Y es que la definición de acoso sexual laboral de la que se parte tiene que actuar como referente de cara a tomar decisiones sobre la metodología a emplear. Por esa razón, se torna imprescindible profundizar en la estructura conceptual de la realidad a analizar.

Tras la reflexión sobre el concepto de acoso sexual laboral y sus implicaciones, cabe concluir la siguiente serie de consideraciones y orientaciones en un intento de respuesta a los interrogantes inicialmente planteados:

- Al ser el acoso sexual un fenómeno tan ambiguo, tanto en intervenciones como en investigaciones sociales conviene no limitarse a plasmar su definición, sino también explicar detalladamente en qué consiste para que sea comprendido con mayor facilidad.

- Las personas potencialmente acosadas pueden ser tanto mujeres como hombres, aunque porcentualmente sea un fenómeno que afecte mayoritariamente a las primeras. Ambos sexos han de estar protegidos en los protocolos de actuación y, dependiendo de los objetivos de cada investigación, representados o no en su universo y muestra.

- El acoso sexual laboral puede provenir también de compañeros/as o incluso clientes, no sólo de superiores jerárquicos. Esta realidad, que es siempre tenida en cuenta en las investigaciones, no lo es entre el común de los/as trabajadores/as no especializados/as en la materia. Por ello conviene clarificarlo en la definición de acoso sexual laboral e incidir en ello en los contenidos formativos de los protocolos.

- El acoso sexual laboral incide en la dinámica relacional de las personas que comparten espacios dentro de la organización laboral. Afecta al personal contratado por empresas de trabajo temporal, afecta al personal en prácticas, etcétera. Estos colectivos han de ser incluidos en la protección otorgada por los protocolos y tenidos en cuenta a la hora de medir el fenómeno si no se quiere negar una parte importante del alcance del mismo.

- Las conductas susceptibles de ser catalogadas como de acoso sexual laboral han de ser "sexuales" en sentido estricto, tanto a la hora de proteger a los/as trabajadores/as a través de un protocolo como a la hora de investigar el fenómeno. Dotar al concepto de mucha amplitud no es operativo a la hora de establecer sanciones, a la hora de facilitar su comprensión y a la hora de medirlo, si engloba bajo una misma denominación situaciones muy divergentes.

- El acoso sexual laboral se puede manifestar a través de chantajes sexuales y a través de acoso ambiental. Ambos han de ser medidos para valorar su incidencia 
y/o prevalencia en los estudios y ambos han de ser explicados y protegidos en los protocolos de actuación.

- Calificativos como "indeseadas" y "no buscadas" no son muy adecuados para describir la percepción de la persona que recibe las conductas sexuales, en el sentido de que facilitan la introducción de errores de atribución, culpando a quien es acosado/a de haber propiciado esa situación. El de "ofensivas" evita ese peligro y se ajusta más a la vivencia del acoso sexual laboral. Por ello proponemos la utilización de ese calificativo en las preguntas sobre la vivencia de acoso sexual y en la definición del fenómeno fijada en los protocolos.

- Dada la importancia de las percepciones sociales en la determinación de lo que es y no es acoso sexual laboral, sería interesante poder contar con más estudios centrados en este objeto de estudio. En ese sentido, las metodologías cualitativas adquieren un especial protagonismo que no han tenido hasta el momento, ya que tradicionalmente la investigación sobre acoso sexual ha estado más orientada a medir la incidencia y prevalencia del mismo sobre la población trabajadora.

- Respecto a la reacción de la persona acosada frente a la acosadora, dada la naturaleza del fenómeno y sus implicaciones, no sería exigible inmediatez y contundencia, sino que bastaría una señal del carácter no querido de tal conducta para deshacer cualquier equívoco o ambigüedad al respecto. Conocer la reacción añade información al estudio del fenómeno, pero la comunicación de la ofensa al interlocutor/a no es un requisito tan importante para considerar una conducta como acoso sexual teóricamente, como para penalizarla en la práctica.

\section{Bibliografía}

Aeberhard-Hodges, J. (1996). Jurisprudencia reciente sobre el acoso sexual en el trabajo. Revista Internacional del Trabajo. Vol. 115, Núm. 5, 543-581.

Alemany Gómez, M. C., Mozo González, C. y Luc, V. (2000). El acoso sexual en diferentes sectores económicos en Andalucía y Cataluña. Madrid: Instituto de la Mujer. Ministerio de Trabajo y Asuntos Sociales.

Ballesteros Doncel, E. (2010). La igualdad de oportunidades y el modelo neoliberal de desarrollo económico: Un matrimonio mal avenido. Sociología del Trabajo. Núm.70, 65-84.

Calle Fuentes, M.; González Romero, C. y Nuñez Triguero, J.A. (1988). Discriminación y acoso sexual a la mujer en el trabajo. Madrid: Largo Caballero.

De la Fuente Vázquez, D. (1998). Análisis de la negociación colectiva en la Comunidad Foral de Navarra desde la perspectiva de género. Navarra: Instituto Navarro de la Mujer. 
Del Rey Guanter, S. (1993). Acoso sexual y relación laboral. Relaciones Laborales. Núm. 1, 228-238.

Directiva 2002/73/CE del Parlamento Europeo y del Consejo, de 23 de septiembre de 2002, Disponible en http://www.boe.es/doue/2002/269/L00015-00020.pdf [consulta: 10-1-2012]

Directiva 2006/54/CE del Parlamento Europeo y del Consejo, de 5 de julio de 2006, relativa a la aplicación del principio de igualdad de oportunidades y igualdad de trato entre hombres y mujeres en asuntos de empleo y ocupación, Disponible en http://eurlex.europa.eu/smartapi/cgi/sga_doc?smartapi!celexplus!prod!DocNumber\&lg=e s\&type_doc $=$ Directive\&an_doc $=2006 \&$ nu_doc $=54$ [consulta: $10-1-2012$ ]

Emer Estudios (1994). El acoso sexual de la mujer en el trabajo. Valencia: Institut de la Dona.

Escudero Rodríguez, R.; Escudero Prieto, A.; Fabregat Monfort, G.; Mendoza Navas, N.; Menéndez Calvo, R.; Roldán Martínez, A.; Serrano García, J.M y Otaegui Jáuregui, A. (2008). Orientaciones y herramientas para incorporar la igualdad de género en la negociación colectiva. Madrid: Instituto de la Mujer, Ministerio de Asuntos Sociales.

Ibáñez González, M.; Lezaun Barreras, Z.; Serrano Argüeso, M. y Tomás, G. (2007). Acoso sexual en el ámbito laboral. Su alcance en la C.A. de Euskadi. Deusto: Universidad de Deusto.

Inmark Estudios (2006). El acoso sexual a las mujeres en el ámbito laboral. Madrid: Instituto de la Mujer, Ministerio de Trabajo y Asuntos Sociales.

Ley 3/1989, de 3 de marzo, por la que se amplia a dieciséis semanas el permiso por maternidad y se establecen medidas para favorecer la igualdad de trato de la mujer en el trabajo, Disponible en http://www.boe.es/boe/dias/1989/03/08/pdfs/A06504-06505.pdf [consulta: 15-1-2012]

Ley 31/1995, de 8 de noviembre, de Prevención de Riesgos Laborales, Disponible en http://www.boe.es/boe/dias/1995/11/10/pdfs/A32590-32611.pdf [consulta: 15-1-2012]

Ley Orgánica 10/1995, de 23 de noviembre, del Código Penal, Disponible en http://www.boe.es/boe/dias/1995/11/24/pdfs/A33987-34058.pdf [consulta: 15-1-2012]

Ley Orgánica 11/1999, de 30 de abril de modificación del Título VIII del Libro II del Código Penal, aprobado por Ley Orgánica 10/1995, de 23 de noviembre, 
Disponible en http://www.boe.es/boe/dias/1999/05/01/pdfs/A16099-16102.pdf [consulta: $15-1-2012$ ]

Ley Orgánica 15/2003, de 25 de noviembre, por la que se modifica la Ley Orgánica 10/1995, de 23 de noviembre, del Código Penal, Disponible en http://www.boe.es/boe/dias/2003/11/26/pdfs/A41842-41875.pdf [consulta: 15-1-2012]

Ley Orgánica 3/2007, de 22 de marzo, para la igualdad efectiva de mujeres y hombres, Disponible en http://www.boe.es/boe/dias/2007/03/23/pdfs/A1261112645.pdf [consulta: 15-1-2012]

MacKinnon, C.A. (1979). Sexual Harassment of Working Women. Londres: Yale University Press.

Martín Serrano, M. y Martín Serrano, E. (1999). Las violencias cotidianas cuando las víctimas son mujeres. Madrid: Instituto de la Mujer, Ministerio de Trabajo y Asuntos Sociales.

Mejías García, A. (1991). El acoso sexual en el trabajo. Análisis y propuestas para su prevención. Madrid: Unión General de Trabajadores.

Nicolson, P.; Ussher, J. y Compling, J. (1992). The Psychology of Women's Health and Health Care. London: MacMillan Press.

Osborne Verdugo, R. (2009). Apuntes sobre la violencia de género. Barcelona: Bellaterra.

Pernas Riaño, B.; Olza, J. y Román, M. (2000). El acoso sexual en el trabajo en España. Madrid: Paralelo Edición.

Real Decreto Legislativo 1/1995, de 24 de marzo, por el que se aprueba el texto refundido de la Ley del Estatuto de los Trabajadores, Disponible en http://www.boe.es/boe/dias/1995/03/29/pdfs/A09654-09688.pdf [consulta: 10-1-2012]

Real Decreto Legislativo 5/2000, de 4 de agosto, por el que se aprueba el texto refundido de la Ley sobre Infracciones y Sanciones en el Orden Social, Disponible en http://www.boe.es/boe/dias/2000/08/08/pdfs/A28285-28300.pdf [consulta: $10-1-2012]$

Recomendación 92/131/CEE, de 27 de noviembre de 1991 relativa a la protección de la dignidad de la mujer y del hombre en el trabajo, Disponible en http://vlex.com/vid/recomendacion-dignidad-mujer-hombre-15456821 [consulta: 13-1-2012] 
Recomendación General No 19 relativa a la violencia contra la mujer, Disponible en http://www.un.org/womenwatch/daw/cedaw/recommendations/recomm-sp.htm [consulta: 1-1-2012]

Rodríguez Sumaza, C. y Luengo Rodríguez, T. (2003). Un análisis del concepto de familia monoparental a partir de una investigación sobre núcleos familiares monoparentales. Papers. Revista de Sociología, Núm. 69, 59-82.

Rubenstein, M. y de Vries, I.M. (1993). How to combat sexual harassment at work. A guide to implementing the European Commission code of practice. Luxemburgo: Commission of the European Communities.

Serrano Argüello, N.; Rey Martínez, F. y Mata Martín R. (2009). Estrategias para la prevención y control del acoso sexual en el empleo. Valladolid: Junta de Castilla y León, Consejería de Economía y Empleo.

Stockdale, J. (1993). La mujer en el mundo del trabajo: perspectivas psicológicas y organizativas. Barcelona: Ediciones Morata.

Wise, S. y Stanley, L. (1992). El acoso sexual en la vida cotidiana. Barcelona: Paidós. 